\title{
BIG DATA ANALYTICS IN BANKING AND FINANCIAL SERVICES SECTOR
}

\author{
${ }^{1}$ Dr.P.V. Mohini \\ Associate Professor, Department of Management Studies, Gayatri Vidya Parishad College for Degree \\ and PG Courses (A), Visakhapatnam
}

\author{
${ }^{2}$ Mr. Rohit Kumar Srivastav \\ II MBA Student, Department of Management Studies, Gayatri Vidya Parishad College for Degree and \\ PG Courses (A) Visakhapatnam
}

Article DOI: https://doi.org/10.36713/epra6558

\begin{abstract}
'He who holds the wealth of information, holds the solution to the toughest of the situations' this quote is very much apt for the recent ongoing scenario, where there is an invisible struggle going on among the organizations as well as nations in the search for more and more information. Now, when the Banking and Financial services sectors are put under the scanner, it becomes evident that they are sitting on top of a humungous heap of valuable data. This data can be used for the betterment and advancement of the industry as well as the people. While it is good to have large amount of data available, it will be termed a big pile of trash if it is not analyzed properly and the results obtained from it are not put to use. With the adoption of Big Data analytics into the banking and financial services, many obvious as well as concealed problems can be addressed to and even solved quickly. The main objective of this paper is to highlight the meaning of Big Data analysis, study the types of data analytics with respect to Banking and Financial services sector and to showcase the potential benefits of embracing Big Data analytics into the Banking \& Financial services sector.
\end{abstract}

KEYWORDS: Information, Banking and Financial services, Advancement, Big Data, Data Analytics

\section{INTRODUCTION}

In todays technology driven world, one thing that has increased by leaps and bounds are the tons and tons of user data that is floating around in the cloud. Especially when we talk about the Banking and Financial services sector, they have a huge database of customers which they have accumulated over a period of time. It is like sitting on a mine of gold, where the important thing is not just mere possession of the mine but the extraction of gold from the mine. In order to take complete advantage of the data that is collected by them, proper analysis is required. This analysis cannot happen with the usage of traditional methods and requires more sophisticated. Big Data Analytics when integrated with Banking and Financial Services sectors enables them to tap into the bulk load of data and use them for their competitive advantage all the while increasing the customers satisfaction levels. 


\section{EPRA International Journal of Research and Development (IJRD)}

Volume: 6 | Issue: 3 | March 2021
- Peer Reviewed Journal

\section{OBJECTIVES}

- To understand the meaning of Big Data Analysis.

- To identify various components of data analytics with respect to banking and financial services sector.

- To showcase the potential benefits of embracing Big Data Analytics into the Banking and Financial services sector.

\section{METHODOLOGY}

This study is done by referring theoretical data available from various online resources. This is purely a theoretical paper.

\section{MEANING OF BIG DATA\& BIG DATA ANALYTICS}

The meaning of the word 'Big Data' is exactly the same as it is read, i.e. collection of large number of data sets. The word 'Big' is attached with 'Data' because it is related to such large unprocessed data which is beyond the scope of traditional databases management tools to capture, process, analyze and store. One of the most important features of Big data is that it keeps on growing exponentially with time. In order to take complete advantage of the data it has to be analyzed critically, this process of analyzing the large data using various tools and techniques is known as Big Data Analytics. With the help of sophisticated software and tools predictive analysis, data mining, text mining and data optimization can be done. Many underlying patterns and upcoming trends are identified using data analytics which helps in making important decisions.

\section{HISTORY \&EVOLUTION OF BIG DATA ANALYTICS}

The concept of Big data is not a new one and it has been around for many years but it has become more popular and needed since the last decade or so. Organizations have started to realize the hidden value of large data sets and use them for their own benefit. But in the olden days when no one knew the existence of big data analytics it was still being used in a more traditional manner in the form of spreadsheets which were manually examined to identify trends and patterns to derive at a conclusion. One of the earliest forms of big data analysis which was used was statistical analytics. But it had a limitation by which it could not analyze huge data all together. This was in the early 1800 s where statistical analysis revolved collection and interpretation of small to medium size of data sets. But in this era big data analysis has become like a necessity for medium to large organizations as they bring with them many advantages over traditional analysis such as they are highly efficient, accurate as well as quick in nature. This gives the organizations and ability to stay one step ahead of the competition.

Below presented pie chart shows the breakup of various industries or sectors which have adopted Big Data Analytics into their ecosystem (Source: IDC Semiannual Big Data \& Analytics)

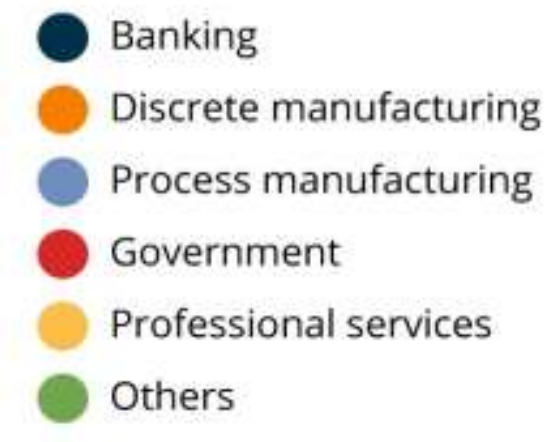

A pie chart showing the various services where Big Data Analytics in adopted at a global level (Source: PWC Global Fintech Report) 


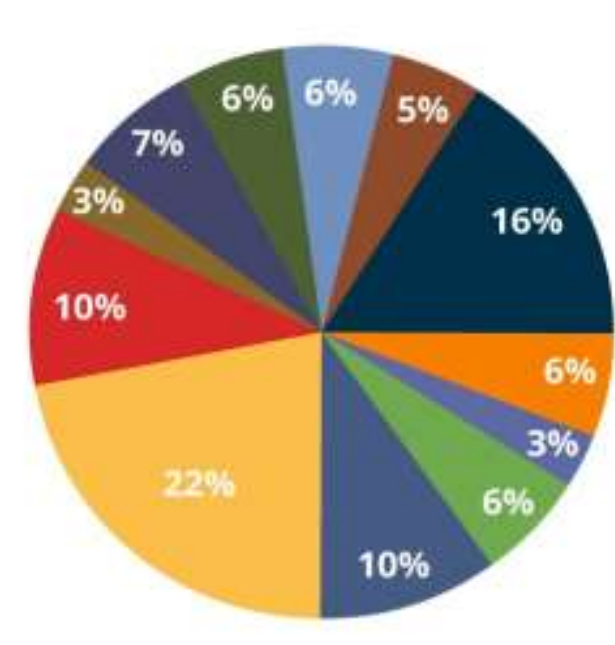

\author{
Data analytics for risk \\ Asset allocation automation \\ Digital experience with human support \\ Enable investments in new markets \\ Standardize customer experience \\ across all points of contact \\ Lower time-to-market for new offerings \\ Alternative marketing and distribution channels \\ New products for traditionally unprofitable customers \\ Brokerage service, investment decision support \\ Custom investment solutions \\ Crowdsourcing, investment decisions \\ Blockchain
}

\section{TYPES OF DATA ANALYTICS}

When we talk about bankingand financial sector, they are highly data intensive industries. The amount of data collected by bankingand financial industries is unimaginable as this is the most basic service which every individual avail. These industries have become more and more data intensive since the digitalization of banking sector as well as financial services sector. Now to utilize this data in a fruitful manner lot of background analytics has to be done, so that the data collected does not go to waste and industry gets good amount of profit out of it. When we talk about data analytics with respect to bankingand financial services sector, they can be divided into 4 main classifications.

Descriptive Analytics

Diagnostic Analytics

Predictive Analytics

Prescriptive Analytics

Descriptive Analytics: Descriptive analytics can be termed as the most basic form of analytics. Here, the mighty data or the large sum of data is basically crunched into such a form that it is understandable. This stage or type is often considered as the first stage of data analytics. Descriptive analytics involves the usage of descriptive statistics like arithmetic operations, mean, median, percentage etc. Now a day's what is called as business intelligence is basically the usage of descriptive analytics to make the raw data understandable to the investors, managers and the stake holders. The main motive is to understand the underlying behavior or trend of the data rather than making any final estimation or conclusions. Banking industry heavily relays on this kind of analytical method as this makes them easy to understand the potential customers spending habit, the investment behavior as well as the savings nature.

Diagnostic Analytics: Diagnostic analytics uses historic data to determine or to get the answer for the question "Why has something happened?" It dives deep into the data and tries to identify the root cause of the problem. This have very much limited usage because this just answers the question of 'why?' and this is limited to only few sectors or industries. The relevance of this kind of analytical tool is very much limited to banking and financial services sectors because this is mainly used to identify the problems which have been occurred with the past performance or why the sales have gone down or why the company has performed poor while all the conditions were favorable instead of trying to analyze or trying to understand the underlying behavior or predict the future.

Predictive Analytics: Predictive analytics as the name itself suggest tries to predict the future occurrence of an event or an instance which is most like going to affect the future performance of the organization. Predictive analytics basically tries to answer the question 'What is likely to happen in future because of some underlying trend in the past historical data'. This has a much wider scope when compared to Diagnostic Analytics as well as Descriptive Analytics because this uses the method as well as the finding of both of them to arrive at a conclusion. The financial service sector can benefit with the usage of this type of analytical method.One 


\section{SJIF Impact Factor 2021: 7.13| ISI I.F.Value:1.241| Journal DOI: 10.36713/epra2016 \\ ISSN: 2455-7838(Online) \\ EPRA International Journal of Research and Development (IJRD)}

Volume: 6 | Issue: 3 | March 2021

- Peer Reviewed Journal

thing is to be considered here is that it is not 100 percent accurate. The findings or the conclusion of this method is purely dependent on the data which is collected. The quality of the data is very much important when compared to the quantity of the data.

Prescriptive Analytics:Prescriptive analytics tries to provide answer to the question 'What action is to be take when a certain situation is experienced?' This is the most sophisticated type of analytics when compared to the other three because it uses the findings, the nature and the method of those three combined together. The main purpose of this type of analytical method is to provide the answer to what is to be done when a particular ill situation or particular problem is encountered. This method is considered to be the smartest way of analytics because it used predictive analytics as its base and it has system of learning at every stage from the feedback provided. Prescriptive analytics uses machine learning, $\mathrm{R}$ programming, python etc. to do the analytical work. It has a lot of significance on banking and financial service sector because this is basically a customer oriented analytical method. It not only uses the internal but also the external data as well as the feedback provided by customers to keep on learning and provide best solution to the users.

\section{BENEFITS OF BIG DATA ANALYTICS IN BANKING \& FINANCIAL SERVICES SECTOR}

When we talk about the potential benefits of associated with the usage of Big Data Analytics, there are many, but in this paper, we try to study only the benefits or advantages which are purely related to the Banking and Financial Services sectors. Some of the most prominent benefits are as follows:

a) Fraud detection \& prevention: Banking and Financial Services industries are both highly secure industries but still they are considered to be one of the most vulnerable ones. We have seen in the recent times that one of the greatest challenges banking industry face are fraudulent activities. These fraudulent activities can be detected and then prevented using Data Analytics, as the analytics runs in the background trying to identify and establish trends and then pin point any undulation in the smooth flow of normal activities, it identifies any strange behavior or irregular transactions and has the ability to stop the fraud before it happens.

b) Segmentation of Customers: A bank or a financial intuition has many customers from different group of income, occupation, net worth etc. They can easily classify or segment their consumers or customers with the usage of data analytics considering various parameters like spending behavior, credit usage and repayment, net worth, services which are frequently used etc. this is possible only using Big Data Analytics because it is not easy task to segment the customer base which is in millions in numbers.

c) Personalization of services: In order to take advantage of personalization of services using data analytics, segmentation of the customers is to be done and basing on the results obtained from various parameters like spending habit, repayment capacity and frequency etc. analysis is done to understand what kind of service is more suited to which category of customers. Here banks and financial institutions can directly target their prospective customers.

d) Customer Lifetime Value: Organizations nowadays are not only focused on making a one-time profit from sale in fact they have become more future conscious and have adopted the method of customer retention. This was earlier practiced only by productbased companies but nowadays even servicebased companies have adopted this. Analytics facilitate the use of customer lifetime value which means the value which a bank or a financial institution will gain after fostering a long-term relation with a customer or a group of prospective customers.

e) Feedback Management:Big data analytics specially in service-based industries like banking and financial services industry mainly derives their external input from the feedback provided by the users, especially perspective analytics which works by using the feedbacks provided. Properly using the feedback helps to improve the quality of the service provided.

f) Increased Efficiency in Operations:The services provided by banking as well as financial institutions may be monotonous in nature but the frequency is very high as there is a huge customer base. There is a necessity for their operations to be highly efficient in nature. Big Data Analytics helps in increasing the efficiency of the operations.

\section{CONCLUSION}

Banking and Financial Service sector which is already a data intensive industry will keep on getting more and more data oriented because the database of 


\section{SJIF Impact Factor 2021: 7.13| ISI I.F.Value:1.241| Journal DOI: 10.36713/epra2016 \\ ISSN: 2455-7838(Online) EPRA International Journal of Research and Development (IJRD)}

the customers is increasing day by day especially after digitalization of banking activities as well as the financial activities in our country. Now using the data accumulated from various customers is in the hands of banks and financial industries because if this data is not utilized properly and just collected, it would be known as the fools' errand. Utilizing it properly would help the battle many unforeseen problems which are lurking around in the future. To battle such problems analytics have paved a path for all the industries, specially banking and financial industries because they directly deal with money and money matters. Wise usage of data and critical examination of data will provide banks and other financial companies a very much competitive advantage. While there are a wide range of advantages of using big data analytics in banking and finance service industry there are also few disadvantages like cost involved, the expertise, the dynamic nature of the operations, the complexity of the work involved but apart for these the advantages outweigh the disadvantages and it would always be advisable to adopt Big Data Analytics in a full pledged manner. To tell it in more simple word, the banking and financial industries are one of the most vulnerable sectors in any country. Big data analytics and various other analytics help to protect these vulnerable industries from other outside threats.

\section{REFERENCES}

1. White Papers, Data Analytics in Banking and Financial Services

2. https://www.osganalytics.com/data-analytics-inbanking-and-financial-services

3. Deena Zaidi, Data Analytics in Banking, October 7, 2017

4. https://www.datasciencecentral.com/profiles/blogs/ data-analytics-in-banking

5. Amit Garg, Davide Grande, Gloria Macías-Lizaso Miranda, Christoph Sporleder, and Eckart Windhagen, Analytics in Banking: Time to realize the value

6. https://www.mckinsey.com/industries/financialservices/our-insights/analytics-in-banking-time-torealize-the-value

7. Anurag, 10 ways Predictive Analytics can help the Banking Sector, April 14, 2017

8. https://www.newgenapps.com/blog/10-wayspredictive-analytics-help-the-banking-sector

9. Justin Prichard, How Banks use Predictive Analytics for service, marketing and security, March 20, 2019

10. https://www.thebalance.com/how-banks-usepredictive-analytics- 4178221

11. Alex Bekker, 4 Types of Data Analytics to improve decision making, July 11, 2017

12. https://www.scnsoft.com/blog/4-types-of-dataanalytics
13. Karsten Egetoft, Data-driven Analytics: Practical use cases for Financial Services, January 29, 2019

14. https://www.digitalistmag.com/customerexperience/2019/01/29/data-driven-analyticspractical-use-cases-for-financial-services06195123

15. Vladimir Fedak, Big Data Analytics in Banking sector, May 29, 2019

16. https://medium.com/datadriveninvestor/big-dataanalytics-in-the-banking-sector-b7cb98d27ed2 